https://helda.helsinki.fi

\title{
Long-term outcomes of oesophageal atresia without or with proximal tracheooesophageal fistula - Gross types A and B
}

\section{Koivusalo, Antti I.}

2017-10

Koivusalo , A I , Sistonen , S J , Lindahl , H G , Rintala , R J \& Pakarinen , M P 2017 , ' Long-term outcomes of oesophageal atresia without or with proximal tracheooesophageal fistula - Gross types A and B ' , Journal of Pediatric Surgery , vol. 52 , no. 10 , pp. 1571-1575 . https://doi.org/10.1016/j.jpedsurg.2017.04.021

http://hdl.handle.net/10138/298135

https://doi.org/10.1016/j.jpedsurg.2017.04.021

publishedVersion

Downloaded from Helda, University of Helsinki institutional repository.

This is an electronic reprint of the original article.

This reprint may differ from the original in pagination and typographic detail.

Please cite the original version. 


\title{
Long-term outcomes of oesophageal atresia without or with proximal tracheooesophageal fistula - Gross types A and B
}

\author{
Antti I. Koivusalo *, Saara J. Sistonen, Harry G. Lindahl, Risto J. Rintala, Mikko P. Pakarinen \\ Section of Paediatric Surgery, Children's Hospital, University of Helsinki, Finland
}

\section{A R T I C L E I N F O}

\section{Article history:}

Received 9 December 2016

Received in revised form 24 March 2017

Accepted 27 April 2017

\section{Key words:}

Oesophageal atresia

Primary repair

Gastric tube

Colon interposition

Jejunum interposition

\begin{abstract}
A B S T R A C T
Purpose: Because of an extended gap between esophageal pouches a variety of methods are employed to treat oesophageal atresia (OA) without (type A) or with (type B) proximal tracheooesophageal fistula. This retrospective observational study describes their single centre long-term outcomes from 1947 to 2014.

Methods: Of 693 patients treated for OA 68 (9.7\%) had type A $(n=58,8.3 \%)$ or $B(n=10,1.4 \%)$. Hospital records were reviewed. Main outcome measures were survival and oral intake.

Results: Nine (13\%) patients had early and 10 (15\%) delayed primary anastomosis, 30 (44\%) underwent reconstruction including colonic interposition $(n=13)$, reversed gastric tube $(n=11)$ and jejunum interposition $(n=6)$, whereas19 (28\%) had died without a definite repair. Median follow up was 35 (interquartile range, $7.4-40$ ) years. Thirty-one (63\%) of 49 patients with definitive repair survived long term. Survival was $22 \%$ for early and $80 \%$ for delayed primary anastomosis, $57 \%$ for colon interposition, $82 \%$ for gastric tube and $84 \%$ for jejunum interposition. Gastrooesophageal reflux was most common after gastric tube (80\%), dysphagia after colon interposition (50\%), and $3(60 \%)$ of 5 survivors with jejunum interposition had permanent feeding ostomy because of neurological disorder. Endoscopic follow-up disclosed no oesophageal cancer or dysplasia. Repair in the most recent patients from 1985 to $2014(\mathrm{n}=14)$ included delayed primary anastomosis $(\mathrm{n}=7)$, jejunum interposition $(n=6)$ and gastric tube $(n=1)$ with $93 \%$ long-term survival.

Conclusion: Morbidity among long-term survivors of type A or B OA is high. With modern management survival is, however, excellent and patients without neurological disorder achieve full oral intake either after primary anastomosis or reconstruction.

Levels of evidence: IV.
\end{abstract}

(C) 2017 Elsevier Inc. All rights reserved.
Successful repair of oesophageal atresia (OA) may be viewed an index measure of professionalism of a pediatric surgical service. Repair of OA without TEF (pure OA) or with proximal TEF (Gross types A and $\mathrm{B}$ ) is almost invariably complicated by a long gap between upper and lower esophageal pouches [1]. The length of the gap, however, varies from patient to patient and depends heavily on measurement technique. Consequently, pediatric surgeons may choose from several surgical options, which include delayed primary anastomosis with or without preceding traction techniques and esophageal replacement with colon, stomach or jejunum. Although oesophageal continuity is nowadays achievable in practically all OA patients, significant longterm morbidity and limitations in oesophageal function remain common $[2,3]$.

In our centre OA repairs have been performed since 1947 for almost 700 patients. In this retrospective observational study we assessed our

\footnotetext{
* Corresponding author at: Children's Hospital, University of Helsinki, Stenbackinkatu 11, PL 281, 00290 Helsinki, Finland. Tel.: + 358 504272512; fax: + 35894714705. E-mail address: antti.koivusalo@hus.fi (A.I. Koivusalo).
}

experience on the type of repair in relation to surgical complications and long-term outcomes in patients with OA of Gross type A or B.

\section{Methods}

Ethical consent from the local board was obtained. Patients with type A or B OA were identified with the help of manual operation theater diary kept from 1947 to 1997 and from computerized archives with the help of ICD codes from 1980 to 2014. Data was collected by review of the hospital records. Diagnosis of A and B type OA was based on gasless gastrointestinal tract in plain X-rays, and from the 1970s onwards by confirmation of the absence of TEF or the presence of proximal TEF with routine preoperative bronchoscopy by the operating surgeon. Reliable details of the gap measurement with the help of fluoroscopy, endoscopy or other methods were available in the latest period of the study from 1985 to 2014. Main outcome measures were survival and degree of oral intake. Surgical complications were also recorded and assessed. Statistical calculations were made with StatView ${ }^{\circledR} 512 \mathrm{com}-$ puter programme (Brain Power, Calabasas CA, USA). Data are presented 
as frequencies or medians with interquartile range (IQR). Categorical variables were compared with Fisher's Exact Test. P values under 0.05 were considered statistically significant.

\section{Results}

From 1947 to 2014 we treated a total of 693 patients with OA. Of these a total of 68 (9.8\%) patients had Gross type $A(n=58,8.3 \%)$ or B ( $\mathrm{n}=10,1.4 \%)$ with Gross type B OA. Median birth weight was $2320 \mathrm{~g}$ (2000-2645), and in three (4\%) patients birth weight was under $1500 \mathrm{~g}$. Sixteen patients (24\%) had a significant congenital heart defect, 13 (18\%) a chromosomal anomaly and 10 (14\%) a gastrointestinal anomaly.

All patients underwent gastrostomy and cervical oesophagostomy or upper pouch suction before esophageal repair. From 1951 to 2014 definitive surgical repair was attempted in 49 (72\%) patients (type $\mathrm{A}, \mathrm{n}=$ 42; type $B, n=7$ ) patients. Surgical techniques are presented in Table 1. Nineteen (28\%) patients from 1947 to 1981 died without any attempt on definite repair. Before 1970 definite repair was attempted in $42 \%$, from 1970 to 1992 in 84\% and from 1993 to 2014 in 100\% of patients.

Nine patients underwent early primary anastomosis at the first or second day of life, whereas 10 patients underwent delayed primary anastomosis at the median age of 2.5(1.5-3.5) months. Oesophageal reconstruction was used in 30 patients. Interposed left colon was used in 13 patients at median age 13 (7-16) months. Colon conduit was placed retrosternally in seven and through posterior left thorax in six patients $[4,5]$. Eleven patients underwent oesophageal reconstruction with Heimlich type reversed gastric tube at the median age of 12 (12-14) months [6]. Reversed gastric tube reconstruction was performed in two stages by constructing the gastric tube by stapling along the greater curvature of the stomach. The tube was brought to the skin at the neck beside the cervical oesophagostomy. At second stage after 2 months, cervical esophagus and gastric tube were anastomosed. Pedicled jejunum interposition was performed from 2005 onwards at median age 7 (2-12) months by using the technique described by Katsura and Bax $[7,8]$. In all six patients the jejunal pedicle was placed orthotopically in the posterior mediastinum through right thoracotomy and anastomosed with the cervical esophagus just below upper thoracic aperture. Right-sided aortic arch in one patient posed no technical difficulty.

\subsection{Mortality after definite repair}

Among the patients who underwent definite repair, 10 died shortly or within a year after surgery owing to necrosis of colon conduit $(\mathrm{n}=$ 4 ), recurrent tracheooesophageal fistula $(n=1)$, septichemia/pneumonia $(n=4)$ or congenital heart defect $(n=1)$. Eight of the remaining 39 patients died later of adhesion ileus $(\mathrm{n}=1)$, congenital heart defect $(\mathrm{n}=1)$, complications of later colon interposition reoperation $(\mathrm{n}=$ $1)$, chronic obstructive pulmonary disease $(\mathrm{n}=1)$ and pneumonia $(\mathrm{n}=4)$. (Table 2$)$.

Table 1

Techniques of definite surgical repair in 49 patients with type A or B oesophageal atresia by treatment era.

\begin{tabular}{ll}
\hline & Era \\
\hline Early primary anastomosis $(\mathrm{n}=9)$ & $1951-1981$ \\
Delayed primary anastomosis $(\mathrm{n}=10)$ & $1982-2014$ \\
Colon interposition & $1961-1976$ \\
$\quad$-retrosternal (right colon $\mathrm{n}=6$, left colon $\mathrm{n}=1)$ & \\
$\quad$-left thoracic (left colon $\mathrm{n}=6)$ & $1973-2001$ \\
Gastric tube $(\mathrm{n}=11)$ & $2005-14$ \\
Jeunum interposition $(\mathrm{n}=6)$ & \\
Total $(\mathrm{n}=49)$ &
\end{tabular}

Table 2

Long-term survival in 49 patients who underwent definite repair.

\begin{tabular}{llll}
\hline & $\begin{array}{l}\text { Death }<1 \text { st } \\
\text { year }\end{array}$ & $\begin{array}{l}\text { Death }>1 \text { st } \\
\text { year }\end{array}$ & Survived \\
\hline $\begin{array}{l}\text { Early primary anastomosis } \\
\quad(\mathrm{n}=9)\end{array}$ & 5 & 2 & $2(29 \%)$ \\
$\begin{array}{l}\text { Delayed primary }(\mathrm{n}=10) \\
\text { Colon interposition }(\mathrm{n}=13)\end{array}$ & 1 & 1 & $8(80 \%)$ \\
- thoracic $(\mathrm{n}=6)$ & 2 & 0 & $7(57 \%)$ \\
- retrosternal $(\mathrm{n}=7)$ & 2 & 2 & \\
Gastric tube $(\mathrm{n}=11)$ & 0 & 2 & $9(82 \%$ \\
Jeunum interposition $(\mathrm{n}=6)$ & 0 & 1 & $5(83 \%)$ \\
Total $(\mathrm{n}=49)$ & 10 & 8 & $31(63 \%)$ \\
\hline
\end{tabular}

* No significant differences between different groups

\subsection{Reoperations}

Fourteen (37\%) of the 39 patients who survived beyond 1 year underwent major reoperations of the esophagus or a conduit (Table 3). Reoperations included resection of anastomotic stricture and reanastomosis in three (23\%) patients with primary anastomosis, resection and reanastomosis of a strictured proximal anastomosis between a conduit and the cervical esophagus in $2(20 \%)$ patients with colon interposition and in 2 (18\%)patients with gastric tube (\%). Strictures of either the proximal or the distal anastomosis between jejunum and esophagus occurred in three (50\%) of six patients with jejunum interposition. In one patient stricture of the proximal anastomosis was managed successfully by resection and reanastomosis. A similar stricture in another patient was treated with an absorbable polydioxanone (PDS) stent (ELLA-CS, Hradec Králové, Czech Republic). During the subsequent dilatations the patient developed significant hemorrhage after stent erosion into a retro-anastomotic aberrant subclavian artery. After reconstruction of the subclavian artery with a vascular graft a new stent was inserted and the dilatations were resumed. The third patient had leakage in the distal anastomosis and subsequently developed a stricture. Stenting of the stricture with a PDS stent was successful but the patient died of pneumonia in another hospital while awaiting further cardiac surgery pulmonary artery stenosis.

Four (13\%) of the 30 patients with reconstruction underwent reoperation after surviving loss of a conduit (colon interposition, $\mathrm{n}=2$; gastric tube, $\mathrm{n}=2$ ). One patient lost his colon conduit owing to postoperative graft ischemia and subsequently underwent gastric tube reconstruction, but at a later date anastomotic ulcer in the gastric tube eroded into aorta, causing massive hemorrhage and loss of gastric tube. He underwent further oesophageal replacement with a pedicled ileocolic graft. Another patient lost his colon conduit in a late reoperation for a strictured colo-gastric anastomosis and died shortly thereafter. Two patients lost their gastric tube because of perioperative ischemia and subsequently underwent colonic interposition.

Of the 19 patients who underwent primary or delayed primary anastomosis 10 (59\%) underwent anti-reflux surgery 5.4 (4.0-8.1) months after esophageal repair for severe reflux symptoms with $(n=5)$ or without $(n=7)$ recurrent anastomotic stricture. In five patients $(50 \%)$ anti-reflux surgery eventually failed and required a redo fundoplication.

\subsection{Long-term survivors, endoscopic follow-up and oesophageal function}

Of the 49 patients who underwent definite repair a total of 31(63\%) are alive today after a median follow-up 35 (IQR 7.4-40) years. The oldest survivor is from 1963 . Of the 24 patients with definitive repair before 1970 only 2 ( $8 \%$ ) survived (Table 4 ). Endoscopic follow-up ( $>2$ successive endoscopies) included 30 of the 31 long-term survivors. Median length of endoscopic follow-up from the definite repair to the latest endoscopy was 35 (30-37) years after early primary anastomosis, 14 (5.0-18) years after delayed primary anastomosis, 25 (14-36) years after colon interposition, 35 (31-35) years after gastric tube and 4.1(2.2-5.4) years after jejunum interposition. 
Table 3

Major oesophageal reoperations and anti-reflux surgery (ARS) after definite repair of type A or B oesophageal atresia.

\begin{tabular}{|c|c|c|c|c|}
\hline \multirow[t]{2}{*}{ Type of repair / reconstruction } & \multicolumn{3}{|c|}{ Reoperations for } & \multirow[t]{2}{*}{ ARS } \\
\hline & Anastomotic stricture & Graft loss & Total & \\
\hline Primary anastomosis $(\mathrm{n}=12)$ & $3(25 \%)$ & - & $3(23 \%)$ & $10(76 \%)$ \\
\hline Reconstruction; colon $(n=10)$ & $2(20 \%)$ & $2(20 \%)^{*}$ & $4(40 \%)$ & - \\
\hline Gastric tube $(\mathrm{n}=11)$ & $2(18 \%)$ & $2(18 \%)^{* *}$ & $4(36 \%)$ & - \\
\hline Jejunum interposition $(n=6)$ & $3(50 \%)$ & - & $3(50 \%)$ & - \\
\hline Total patients $(\mathrm{n}=39)$ & $10(26 \%)$ & $4 / 30(13 \%)$ & $14(37 \%)$ & $10(26 \%)$ \\
\hline
\end{tabular}

* One early graft loss was revised with gastric tube which in turn was later revised with ileocolonic interposition because of heamorrhagic ulcer, one late graft loss.

** Two early graft losses revised with colon interposition.

Endoscopic follow-up disclosed no dysplastic epithelial changes either in esophageal remnants or in interposed conduits. A patient with gastric tube displayed intestinal metaplasia in the upper esophagus 30 years after the operation. However, in his later follow-up endoscopies no intestinal metaplasia was observed. In the rest of the patients endoscopic examinations have not disclosed intestinal metaplasia, dysplasia, or cancer. Severe ulcerative oesophagitis was diagnosed in one patient who had undergone early primary anastomosis and who had survived for 60 years with years of heavy alcohol and cigarette consumption and died after having myelodysplastic syndrome, pancreatic cancer and chronic obstructive lung disease.

Of the 31 long-term survivors 26 (84\%) enjoy full oral intake, whereas five (16\%) are dependent on feeding gastrostomy $(n=1)$ or jejunostomy $(n=4)$. All the 8 survivors with colon interposition have full oral intake, of the 9 survivors with primary anastomosis one is dependent on feeding jejunostomy, of the 8 survivors with gastric tube one is dependent on feeding jejunostomy and of the 5 patients with jejunum interposition 2 are dependent on jejunostomy and one with gastrostomy. All five patients with a feeding ostomy have a severe neurological disorder (cerebral palsy $n=2$, Down's syndrome $n=2$ and Feingold syndrome $\mathrm{n}=1$ ) and none of them are likely to wean from ostomy feeding.

Twelve (30\%) of the 31 survivors with primary anastomosis $n=4$ (40\%); colon interposition $n=1$ (13\%); gastric tube $n=6(77 \%)$ and jejunum interposition $n=1$, (20\%) have significant gastrooesophageal reflux and require constant medication with protein pump inhibitors $(\mathrm{n}=12)$ or jejunostomy feeding $(\mathrm{n}=2)$. Constant or occasional dysphagia occurred in $11(32 \%)$ of survivors (primary anastomosis $\mathrm{n}=1$ (10\%); colon reconstruction $n=4(50 \%)$; gastric tube $n=3(38 \%)$ and jejunal interposition $n=3$ (60\%). According to pulmonologist follow-up reports (available from 2001 onwards in 10 patients) 4 (40\%) of 10 patients had frequent respiratory infections, regular airway medication and reduced respiratory capacity in spirometry.

\subsection{The recent outcomes from 1985 to 2014}

From 1985 to 2014 we treated 201 patients of whom 14 (7.0\%) had oesophageal atresia type $A(n=10,5.0 \%)$ or $B(n=4,2.0 \%)$, six $(43 \%)$ patients were referred. From1947 to 198554 of 492 (11\%) patients had type $\mathrm{A}(\mathrm{n}=48,9.8 \%)$ or $\mathrm{B}(\mathrm{n}=6,1.2 \%)$ OA. Between these two time periods the relative amount of type A decreased significantly ( $p=0.01$ ) whereas total proportion of types A or B remained unchanged $(p=0.12)$.
As the primary measure all 14 patients underwent gastrostomy and constant upper pouch suction $(\mathrm{n}=12)$ or underwent cervical oesophagostomy $(\mathrm{n}=2)$. Measurement of the gap length under fluoroscopy by inserting endoscopes into the proximal oesophageal pouch and through the gastrostomy to the distal oesophageal pouch was performed in 12 patients. Six (50\%) patients with gap length of 3-4 vertebraes underwent delayed primary anastomosis, and six with gap length of 7-8 vertebrae had jejunum interposition. In two patients endoscopic assessment suggested long proximal oesophageal pouches and consequently delayed primary anastomosis was intended without proper gap measurement. In one patient delayed primary anastomosis was successful but in the other patient the gap remained excessive even after maximal mobilization of the proximal and distal pouches and the operation was conversed into reversed gastric tube. Currently 13 (93\%) of patients are alive. One patient with Down's syndrome and an associated cardiac defect and jejunum interposition died in another hospital of pneumonia while awaiting further cardiac surgery. Of the 13 survivors 8 have full oral intake, whereas 5 with severe neurological disorders remain dependent on feeding ostomy.

\section{Discussion}

Our results in the treatment of type A and B OA reflect the general development in the management of long-gap OA. Up to the 1960s less than $50 \%$ of children with OA survived and prognosis with A or B type atresia was dismal [9]. In contrast our 93\% survival in the most recent period from 1986 to 2014 is very near of the overall survival rate of oesophageal atresia today [2]. Full oral feeding in $85 \%$ of survivors of type A and B oesophageal atresia is a satisfactory result. In the early period of our series definite repair was attempted in less than $50 \%$ of patients and less developed neonatal intensive care was reflected by the high postoperative mortality. Survivors of the definite repair were at high risk of later mortality and among the survivors morbidity was common. During the most recent period of our study the relative amount of type $A$ OA has decreased. The decrease may be explained by the difficulty of distinguishing type A from type B during the very early period of the study or by seasonal variations in the occurrence of type A. Because of its retrospective nature our study has several flaws. In the earliest hospital reports little or no data concerning the length of the gap between oesophageal ends and its effect on the choice oesophageal repair techniques was given, whereas in the most recent part of the study population $85 \%$ of patients had measurement of the gap length by a reliable method. Endoscopic follow-up had no uniform plan and between

Table 4

Long-term survivors of Types A and B oesophageal atresia $(\mathrm{n}=31)$.

\begin{tabular}{|c|c|c|c|}
\hline Original operation & Survivors $(\mathrm{n})$ & Final esophageal repair in survivors & Median (IQR) age (yrs) \\
\hline Early or delayed primary anastomosis $(\mathrm{n}=19)$ & 10 & Primary anastomosis & $26(6-30)$ \\
\hline Colon interposition $(\mathrm{n}=13)$ & 9 & $\begin{array}{l}\text { Thoracic colon conduit, } \mathrm{n}=5 \text { (including two patients with lost gastric tubes) } \\
\text { Retrosternal colon conduit, } \mathrm{n}=3 \\
\text { Ileocolic conduit, } \mathrm{n}=1 \text { (after lost thoracic colon and gastric tube) }\end{array}$ & $46(43-52)$ \\
\hline Reversed gastric tube $(\mathrm{n}=11)$ & 7 & Reversed gastric tube & $36(35-41)$ \\
\hline Jeunum interposition $(n=6)$ & 5 & Jejunum interposition & $5.4(3.2-7.7)$ \\
\hline Total $(n=49)$ & 31 & & \\
\hline
\end{tabular}


individual patients the duration of the follow-up varied substantially. Follow-up data by pulmonologist was only available from 2001 onwards but it is safe to assume that respiratory problems in the rest of the patients were not insignificant. This study, however, enlightens some of the issues associated with long-term outcome after the management of type $\mathrm{A}$ or $\mathrm{B} \mathrm{OA}$.

Of the total number of our surviving patients only one third (50\% of the most recent patients) underwent an early or delayed primary anastomosis and all survivors retained their native esophagus. In previous reports of pure or long-gap oesophageal atresia the percentage of patients who were managed with delayed primary anastomosis varies from $20 \%$ to $100 \%$ [10-15]. Here, the adoption of delayed primary anastomosis increased markedly the chances of survival. Despite the frequent problems with anastomotic strictures and gastrooesophageal reflux all our patients who survived primary anastomosis retained their native esophagus and none died of surgical complications. Owing to a high failure rate of anti-reflux surgery, management of gastrooesophageal reflux in these patients has been challenging, while exposure to constant reflux increases the risk of Barretts esophagus and associated premalignant oesophageal lesions [3,16-18]. Our median 14 years follow-up has not disclosed intestinal metaplasia, epithelial dysplasia or cancer, but frequency of metaplastic epithelial changes increases with advancing age rendering endoscopic surveillance warranted [3].

The ideal method of oesophageal reconstruction is a matter of continuous debate. Although long-term outcomes after various oesophageal reconstructions are often reported as acceptable, the studies vary in their assessment of oesophageal function and may cover only a fraction of the operated patients and there is very limited data on adult survivors [19-25]. The difficulty of the finding of an ideal method of reconstruction is apparent also in our series in which basically three different methods of oesophageal reconstructions including colonic interposition, reversed gastric tube and jejunum interposition were used during different eras. All methods were associated with significant early and late complications and reoperations were frequent. Survival in patients with gastric tube and jejunum interposition was comparable to survival after delayed primary anastomosis. Colonic interposition in children was a demanding operation in the 1960s and survival was the lowest. Nowadays survival after colonic interposition is comparable with other reconstruction methods [22,24]. At our unit, use of colon interposition was replaced by reversed gastric tube owing to frequent technical difficulties and mortality [25]. Although some pediatric surgeons consider colon interposition as a primary choice for reconstruction $[22,24]$, late problems of colon interposition may be substantial. Coopman et al. (2008) reported significant long-term complications including stricture, graft redundancy, dumping, graft obstruction and decreased lung function in 12 (70\%) of 17 patients with oesophageal atresia who underwent colonic interposition [23]. Among our survivors all had full oral intake but half suffered from dysphagia. Despite the apprehensions of cancer development in the graft or in the remaining esophagus signs of malignancy have not been disclosed in long-term endoscopic follow-ups [26,27].

In our series reversed gastric tube reconstruction was associated with graft loss in $20 \%$ and $80 \%$ of survivors had significant gastrooesophageal reflux. The lack of anti-reflux barrier in the anastomosis between cervical esophagus and gastric tube, retained acid secreting capacity of the distal tube together with small volume of the remaining stomach complicate the management of gastrooesophageal reflux and lifelong medication is required [28]. Dysphagia in 38\% of our gastric tube survivors was similar as $43 \%$ reported by Lee et al. (2014). Lee et al. (2014) reported also general gastrointestinal problems in $64 \%$ and respiratory problems in as much as $57 \%$ of patients with gastric tube [11].

To overcome the significant functional problems associated with gastric tube, the most recent esophageal reconstructions were performed with pedicled jejunum interposition in six patients with type
A or B OA. None of the jejunum conduits were lost The overall functional results are affected by the fact that three of the six patients have a significant neurological disorder without the full capacity for oral intake. Two survivors without neurological deficit are doing well and have full oral intake. In addition, we have performed 7 jejunum interpositions in patients with substantial loss of esophagus because of oesophageal perforation $(\mathrm{n}=5)$ or inflammatory pseudotumor $(\mathrm{n}=1)$ and because of recalcitrant anastomotic stricture in C-type $O A(n=1)$. Half of the six type A or B OA patients had recalcitrant anastomotic strictures between the interposed jejunal graft and the remaining esophagus. Whether these strictures can be successfully managed endoscopically with dilatable absorbable stents instead of open resection and reanastomosis cannot be stated with certainty in our small series. Even an absorbable stent may cause complications such as erosion and excess granulation. In one of our patients a stent in a strictured upper anastomosis between cervical esophagus and interposed jejunum usured into retrooesophageal subclavian artery and caused a potentially life-threatening hemorrhage. This complication highlights the importance of routine assessment of mediastinal vessels with contrast enchanced CT- scan in all patients with possibility of esophageal reconstruction.

None of our patients underwent reconstruction by gastric pull-up or delayed anastomosis with traction techniques. Although gastric pull-up is considered as the oesophageal reconstruction method of choice by many surgeons, long-term outcomes include impaired respiratory function, severe gastrooesophageal reflux and small gastric volume, whereas many surgeons are not confident with traction techniques [29]. In our series we could not show the superiority of any of the oesophageal reconstructions. However, patients with type A or B oesophageal atresia are relatively rare and only half of them require oesophageal reconstruction. Although jejunum interposition remains our primary choice of reconstruction, we realize that in individual patients medical conditions or loss of small intestine from previous operations may call for different types of reconstructions including gastric pull-up, free jejunal graft with vascular anastomosis or pedicled jejunal graft supercharged with another cervical vascular anastomosis.

\section{References}

[1] Gross RE. The surgery of infancy and childhood. Philadelphia: PA: WB Saunders; 1953.

[2] Koivusalo AI, Pakarinen MP, Rintala RJ. Modern outcomes of oesophageal atresia: single centre experience over the last twenty years. J Pediatr Surg 2013;48:297-303.

[3] Sistonen SJ, Koivusalo A, Nieminen U, et al. Esophageal morbidity and function in adults with repaired esophageal atresia with tracheoesophageal fistula: a population-based long-term follow-up. Ann Surg 2010;251:1167-73.

[4] Battersby JS, Moore TC. Esophageal replacement and bypass with ascending and part of transverse colon for the treatment of congenital atresia of the esophagus. Surg Gynecol Obstet 1959;109:207.

[5] Waterston D. Colonic replacement of esophagus (intrathoracic). Surg Clin North Am 1964;44:1441.

[6] Heimlich HJ. Reversed gastric tube. Esophagoplasty for failure of colon, jejunum and prosthetic transpositions. Ann Surg 1975;182:154-60.

[7] Katsura S, Ishikaway Okayama G. Transplantation of the partially resected middle esophagus with a jejunal graft. Ann Surg 1958;147:146-56.

[8] Bax NM, van der Zee DC. Jejunal pedicle grafts for reconstruction of the esophagus in children. J Pediatr Surg 2007;42:363-9.

[9] Louhimo I, Lindahl H. Esophageal atresia: primary results of 500 consecutively treated patients. J Pediatr Surg 1983;8:217-29.

[10] Holland AJ, Ron O, Pierro A, et al. Spitz L surgical outcomes of esophageal atresia without fistula for 24 years at a single institution. J Pediatr Surg 2009;44:1928-32.

[11] Lee HO, Hawley A. Doak J, et al. Long-gap oesophageal atresia: comparison of delayed primary anastomosis and oesophageal replacement with gastric tube. J Pediatr Surg 2014;49:1762-6.

[12] Séguier-Lipszyc E, Bonnard A, Aizenfisz S, et al. The management of long gap esophageal atresia. J Pediatr Surg 2005;40:1542-6.

[13] Burjonrappa S, Thiboutot E, Castilloux J, et al. Type a esophageal atresia: a critical review of management strategies at a single center. J Pediatr Surg 2010;45:865-71.

[14] Zani A, Cobellis G, Wolinska J, et al. Preservation of native esophagus in infants with pure esophageal atresia has good long-term outcomes despite significant postoperative morbidity. Pediatr Surg Int 2016;32:113-7.

[15] Rothenberg SS, Flake AW. Experience with thoracoscopic repair of long gap esophageal atresia in neonates. J Laparoendosc Adv Surg Tech A 2015;25:932-5.

[16] Pultrum BB, Bijleveld CM, de Langen ZJ, et al. Development of an adenocarcinoma of the esophagus 22 years after primary repair of a congenital atresia. J Pediatr Surg 2005;40:e1-4. 
[17] Adzick NS, Fisher JH, Winter HS, et al. Esophageal adenocarcinoma 20 years after esophageal atresia repair. J Pediatr Surg 1989;24:741-4.

[18] Jayasekera CS, Desmond PV, Holmes JA, et al. Cluster of 4 cases of esophageal squamous cell cancer developing in adults with surgically corrected esophageal atresiatime for screening to start. J Pediatr Surg 2012;47:646-51.

[19] Ludman L, Spitz L. Quality of life after gastric transposition for oesophageal atresia. J Pediatr Surg 2003;38:53-7.

[20] Spitz L, Kiely E, Pierro A. Gastric transposition in children-a 21-year experience. J Pediatr Surg 2004;39:276-81.

[21] Hirschl RB, Yardeni D, Oldham K, et al. Gastric transposition for esophageal replacement in children: experience with 41 consecutive cases with special emphasis on esophageal atresia. Ann Surg 2002;236:531-9.

[22] Burgos L, Barrena S, Andrés AM, et al. Colonic interposition for esophageal replacement in children remains a good choice: 33-year median follow-up of 65 patients. J Pediatr Surg 2010;45:341-5.
[23] Coopman S, Michaud L, Halna-Tamine M, et al. Long-term outcome of colon interposition after esophagectomy in children. J Pediatr Gastroenterol Nutr 2008;47:458-62.

[24] Tannuri U, Maksoud-Filho JG, Tannuri AC, et al. Which is better for esophageal substitution in children, esophagocoloplasty or gastric transposition? A 27- year experience of a single center. J Pediatr Surg 2007;42:500-4.

[25] Lindahl H, Louhimo I, Virkola K. Colon interposition or gastric tube? Follow-up study of colon-esophagus and gastric tube-esophagus patients. J Pediatr Surg 1983;18:58-63.

[26] Lindahl H, Rintala R, Sariola $\mathrm{H}$, et al. Long-term endoscopic and flow cytometric follow-up of colon interposition. J Pediatr Surg 1992;27:859-61.

[27] Houghton AD, Jourdan M, McColl I. Dukes a carcinoma after colonic interposition for oesophageal stricture. Gut 1989;30:880-1.

[28] Borgnon J, Tounian P, Auber F, et al. Esophageal replacement in children by an isoperistaltic gastric tube: a 12-year experience. Pediatr Surg Int 2004;20:829-33.

[29] Zani A, Eaton S, Hoellwarth ME, et al. International survey on the management of esophageal atresia. Eur J Pediatr Surg 2014;24:3-8. 